DOI: $10.24234 /$ wisdom.v17i1.414

Olena MATUZKOVA, Iryna RAYEVSKA, Olga GRYNKO

\title{
IDENTIFICATION AND IDENTITY: DIFFERENTIATING THE CONCEPTUAL TERMS
}

\begin{abstract}
The relevance of the problem of identity and identification is determined by the changes in sociocultural reality in the post-modern societies of the second half of the $20^{\text {th }}$ century, the crisis in the existential approach to personality studies, enhanced integrative trends in scientific thinking, its humanitarianization and anthropocentric nature.

This research paper looks at the actualization of the studies on identity and identification, describes the history and scope of the identification studies, substantiates the differentiation between the terms of individual/collective identity and identification.

The differentiation of the investigated terms is confined to the fact that identification serves as a foundation for constructing identity, so they correlate as a mechanism, process, and result of such mechanism's operation in an individual self-conscious. Identification is seen as a cognitive-and-emotional mechanism of identity construction, due to which the subject constructs his or her sameness. Identity is a result of recognition and emotional assessment of the individual-and-group and collective characteristics by an individual or group. Such characteristics have been endorsed by the relevant others as a result of constructing the world image, the image of the collective, of individual's or group's self and their place in there, basing on the specific identifying features.
\end{abstract}

Keywords: identity, identification, mechanism, result, differentiation, individual, sameness, identifying features.

Introduction

Identity and identification are complex and comprehensive phenomena, integrating into a single cultural, mental, social, communicative, and linguistic aspects. All their numerous, and, by now, difficult-to-review definitions can be modelled, in this way or the other, down to the following: an identity of either an individual or a group is created via identification of the society where they live, the culture they belong to, and the language they use in their thinking process and communicative activities.

The problematics, currently referred to as "the problematics of identity", has occupied a prominent place in the research of many philosophers, physiologists, and sociologists of the early $20^{\text {th }}$ century. The evolution of identity as a scientific concept during a better part of the $20^{\text {th }}$ century was taking place in three epistemological par- 
adigms: philosophic, psychoanalytical, and sociological. In logics as well as in non-classic and post-classic philosophy, the establishment of the identity concept is integral with the scope of such concepts as "sameness", "differentiation", "individuality", "personality", "personhood", and "other" (Th. Adorno, M. Bakhtin, E. Husserl, G. Deleuze, J. Derrida, S. Kierkegaard, E. Levinas, J. Scott, J. Fichte, J. Habermas, M. Heidegger, M. Scheller, A. Schutz, and many others).

Psychology, social psychology, sociology, and cultural anthropology exploited the concept of "identity" with no correlation to any philosophic interpretation. So, the establishment of this concept followed the footsteps of the evolution of the traditional concepts of "I-ness", "personality", "Self", "self-consciousness", "unconscious", "personal self-determination" etc. (W. James, G. Kelly, Ch. Cooley, J. Lacan, G. Mead, S. Freud, E. Fromm, E. Erikson, and many others).

The focus on the topic of identity in the $20^{\text {th }}$-century scientific paradigm and plethora of investigations in the same vein in the $21^{\text {st }}$ century are primarily associated with the devaluation or, as Z. Bauman, M. Zakovorotnaya, Yu. Malakhov put it, lack of solvency of traditional terminology and notionalness (Bauman, 2010; Zakovorotnaya, 1999; Malakhov, 2011).

Classical and (partially) non-classical philosophy described a human being in terms of the stable existential coherence, equal to itself. Amid the post-modern globalized world, such a fieldspecific existential approach is subject to severe criticism and goes through an overhaul in terms of its fundamental ideas and concepts or is even being entirely rejected by the social sciences. For instance, E. Erikson, when coining the concept of the psychosocial identity into the scientific lingo and criticizing the philosophic guideposts of existentialism, argues that existential sameness of a personality is developed in line with the group identity - not out of it or in opposition to it. V. Abushenko also indicates that we witness "the annihilation of sameness, that at all time belongs with or appeals to the past. It results from the fact that the identity is open to the future and manifests essential incompleteness of a human being" (Abushenko, 1998, p. 403).

As a consequence of such a paradigm shift, not only has the concept of "identity" destroyed the traditional idea about the sameness of a personality, but it also served as a means of ultimate radicalization of the concept of "Self". It has also rechannelled the problematics of the classical and postclassical philosophy to the intersubjectivity space. Such epistemological perspective made it possible to bring into correlation the interpretations of identity in the philosophic and socio-humanitarian scope of knowledge, to avoid unwelcome associations with the "philosophy of mind" and, at the same time, not to restrict such problematics by the frames of psychoanalysis only (Abushenko, 1998; Malakhov, 2011).

Today, identity is the "trendiest" topic in the contemporary humanitarian paradigm. All are speaking about identity; however, a clear, unified definition of its essence has, in fact, never been found. Moreover, at the negative extreme of such discussions, there are numerous claims that identity does not exist at all or it has been lost, as the identity characteristics, traditionally taken into consideration when determining identity - territory, race, ethnicity, gender, class, family - become irrelevant and inconsistent in the so-called "post-modern culture" (Aslet, 1997; Scruton, 2006).

However, today more than ever, the identity, deriving from those cultural-and-value domi- 
nants of the society that are functionally critical at a particular stage of its advancement, is an "immunity", developed by each culture for selfpreservation in the dialogue with other cultures and a mega-culture as a whole. Therefore, the problem of identity is valid and vital in modern society, as it registers the search for possible ways of providing security and protection and harmonic engagement into the specific community of both an individual and a group (Matuzkova, 2014).

Therefore, the relevance of research into the identity and mainstreaming it into the area of socio-humanitarian knowledge are determined by the changes in socio-cultural reality in the postmodern societies of the second half of the $20^{\text {th }}$ century, the crisis in the existential approach to personality studies, enhanced integrative trends in the scientific thinking, its humanitarianization and anthropocentric nature.

Inextricably intertwined with the problematics of identity, the problematics of identification is one of the topical issues of the scientific thought of the late $20^{\text {th }}$ - early $21^{\text {st }}$ centuries. The amount of research addressing the issue of identification in one way or another has been increasing year in and year out. Nevertheless, many issues remain unresolved, pending, controversial, and requiring new theoretical comprehension.

Focus on the issues associated with the problem of identification is becoming increasingly urgent amid the aforementioned modern realia. The need for such research is undoubted and proceeds from the imbalanced system of identification and individual self-identification observed in today's society, resulting in an unstable nature of the individual and group identity. For instance, the destruction of the social system coherence in Russia in the 1990s translated into unpredictable, chaotic changes in individual identity structure.
In post-Soviet Russia, there is a pronounced trend of replacing civil identification of the citizens with nation-based or ethnic-based individual identification (Polezhayeva, 2006; Matuzkova, 2014; Malakhov, 2011).

\section{Research Methods}

The goal, tasks, and methodological basis of the research determined the application of the complex of general scientific methods and operations, namely observations, induction and deduction, analysis and synthesis, taxonomy and modelling to theoretically comprehend, arrange, summarize, catalogue, and describe the scope of research and content of the investigated phenomena of identity and identification. Descriptive analysis was applied for the general description of the characteristic features of identity and identification.

\section{Discussion}

In the scientific-and-research literature, the terms "identification" and "identity" are gaining more comprehensive application and many-sided interpretations. The multiplicity of meanings and interpretations of these concepts are determined, according to our observations, by the different context they are utilized in, including the following: 1) general scientific; 2) humanitarian; 3) interdisciplinary (e.g. within the humanitarian context), 4) disciplinary (e.g. in psychology, sociology, philosophy, cultural studies, ethnology, etc. within the humanitarian context); 5) highly specialized (e.g. in social, engineer, legal psychologies, psychoanalysis, cognitive psychology, ethnopsychology, cultural psychology etc.); 6) highly theoretical (within the theories or research studies of individual scholars). 
For instance, the term "identification" in the general scientific context is determined by the words "authentification", "determination", "assimilation", "recognition", "establishing", "equating", "manifestation", "distinction". The analysis of the main general-science definitions of identification enables us to single out, in fact, two meanings, this word gains in the general-science context: 1. recognition, authentication of something or somebody; 2. assimilation, sameness with someone or something (Polezhayeva, 2004; Mescheryakov \& Zinchenko, 2007; Stenin, 2011, and many others).

In its first meaning, the term "identification" in a general scientific context is understood as the process of comparison of one object to another, based on a feature or property. Therefore, similarity or dissimilarity is established. In its second meaning (mostly typical for humanitarian sciences), identification is the process when an individual unconsciously associates himself or herself with another individual, group, or pattern.

The fundamental research into the term "identification" in the humanitarian context has been conducted in line with the development of philosophy, psychology, sociology and social psychology, culturology, cultural anthropology, ethnology, linguistics, and other sciences. All these sciences engage this term through the investigation of traditional categories of sameness and otherness (T. Adorno; G. Hegel; G. Deleuze; J. Derrida; M. Sheller, and many others), identity problematics (Ch. Cooley; R. Merton; G. Mead; S. Freud; M. Heidegger; E. Erikson, and many others), dialectic pair "friend-or-foe (us-andthem)" (M. Bakhtin; D. Gachev; L. Grishayeva; V. Makhlin; L. Feuerbach; J. Fichte, and many others).

In the recent decades, the studies have been focused on general challenges of the identifica- tion theory, determination of its place in the processes of establishing and functioning of a personality (Z. Bauman; M. Guboglo; V. Malakhov; N. Polezhayeva; V. Spiro, and many others), specific issues of identification, self-identification, and self-consciousness (E. Aleksandrenkov; P. Bychkov; N. Skortsov; V. Khotinets; M. Scherbakov, etc.), as well as the distinguishing features of sex, gender, national, religious, occupational, cultural, and other identifications (Yu. Bovkunova; V. Inozemtsev; V. Malakhov; Ye. Matveeva; S. Huntington; M. Scherbakov; V. Yadov, etc.), and the place and role of identification in the contemporary globalized space (V. Bernatsky, V. Grebner; M. Kaluzhsky; A. Panarin, etc.).

The most numerous and efficient studies relate to ethnic, national identification and selfidentification (V. Badmayev; Yu. Bromley; T. Stefanenko; I. Tatarenko; V. Khotynets, and many others).

In the socio-humanitarian paradigm, the term "identification" was first used by S. Freud ("Group Psychology and Analysis of the Ego", 1921) while interpreting the phenomena of pathological depressions. He also employed it to analyse dreams and specific processes through which a child imbibes the behavioural patterns of the relevant others. The psychoanalysis founder, as well as his disciples, saw identification as an unconscious process of imitation and as the earliest display of an emotional bond between a child and the mother. In this vein, identification was defined as one of the mechanisms that form the moral instance of Super-Ego when a child identifies itself with his or her parents and other relevant people (Boiko, 2008, p. 147; Malakhov, 2004, p. 299; Naumenko, 2003, p. 400).

Later, in non-orthodox psychoanalysis, the identification was interpreted more broadly as a 
mechanism of psychological I-defence from threatening foreign object and the central mechanism of shaping an individual's ability of selfdevelopment. Meanwhile, the subject and object establish a specific bond through which a subject is experiencing its sameness with the object (Boiko, 2008, p. 147; Naumenko, 2003, p. 400).

E. Erikson (1996) extends the concept of identification and argues it is a mechanism of an individual assimilating with a relevant other. It is the individual's self-esteem from the viewpoint of how the others, in his opinion, perceive him in comparison with themselves within the typology that is relevant to them (pp. 31-32).

These fundamental definitions of identification have been actively developed within the psychoanalytical approach to the studies of identity we have mentioned above.

The representatives of the symbolic interactionism interpreted identification as a mechanism and result of the social interaction that enables an individual to compare himself with other people in the process of social communication and look at himself the way the others see him, manifested in the others' relevant responses and actions. In this case, he is looking at himself as a social object with certain features and peculiarities.

The studies, interpreting the identification as a unity of "outside" and "inside" factors for establishing and constructing a personality, influenced further research into the social principles of the identification (L. Vygotsky; E. Goffman; Ch. Cooley and many others). In these studies, framed by the sociological approach to investigating identity, the identification in the most general terms is interpreted as a vital mechanism of personal socialization, enabling an individual to master efficiently various types of social activities (S. Moskovichi; V. Mukhina; B. Porshnev; B. Yadov).
The interdisciplinary cognitive approach to the studies of identity defines identification as a cognitive-and-emotional process where a subject associates himself with another subject or a group that helps him to successfully absorb social norms and values and take on different social roles (Boiko, 2008; Krysko, 2001).

The researchers used to emphasise the exclusively adaptive function of identification in personality development. These days, however, the identification is acknowledged as an emotionally rational act where the subject assigns to himself a certain feature, property, action, condition, or role (Grishayeva, 2007; Katanova, 2007; Polezhayeva, 2006, etc.).

The constructionist approach interprets identification as a process of authentication of what is needed for the system of identity subject to continuous construction. The process comprises sameness and otherness as parity procedures (Polezhayeva, 2006).

Identification is an inherently socio-cultural phenomenon formed within a social activity of an individual and a group. There is a good reason why today, more than ever before, exploring this specific aspect of the investigated phenomenon has gone high on the agenda. In many research pieces, the identification is characterised as one of the mechanisms controlling the bound processes of socialization and enculturation, which, in their turn, construct a social identity (L. Grishayeva; T. Grushevitskaya; E. Katanova; V. Popkov; A. Sadokhin; O. Selivanova).

These are the significant definitions of the term "identification" in the humanitarian context of contemporary scientific knowledge, related to the interdisciplinary approaches to identity research.

Identification is also a subject of disciplinary and highly specific studies. From this view- 
point, it should be mentioned that psychology and sociology generate the most considerable amount of research and interpretations of this concept. A cohort of works on this problem realm is becoming hard to observe, bringing to the spotlight the challenge of unifying the identification concept in the highly specific explorations. The framework of our research paper precludes us from the conclusive review of such investigations. Nevertheless, our observations suggest that the entries on identification in the largest and most reputable discipline-specific dictionaries and encyclopaedias, published in the last thirty years, make this problem quite apparent.

For instance, the authors of the Concise Dictionary of Psychology (Petrovsky \& Yaroshevsky, 1985) suggest five definitions of the term "identification of personality", assigning them to either a highly specific area of application or concurrent areas of mental reality (pp. 108-109). Even in one of the most renowned dictionaries of the recent decade - the Big Dictionary of Psychology, edited by V. Mescheryakov and V. Zinchenko, - identification is interpreted explicitly, yet unclearly. It employs several keywords in broad meanings, such as "association" and "recognition":

1. Situational association of self with a relevant other...;

2. Stable association of self with a relevant other...;

3. Association of self with a fictional character...;

4. A psychological defence mechanism...;

5. Stable association of self with a group...;

6. In engineering and legal psychology, the recognition, detection of certain objects... (Mescheryakov \& Zinchenko, 2007, p. 188).

Such terminological disparity is displayed in the sociological investigations, too. The term "identification" is defined as a process of individual's association with a social group; as a mechanism of socialization of a person through his association with a certain group; as the process and the result of the subject's association with the social group and the way to absorb the social values and norms; and as an acknowledgement of the individual's belonging with a group by the others (V. Anurin; V. Boiko; Z. Golenkova; B. Isayev; A. Kravchenko, etc.).

The critical analysis of certain definitions of identification in the contemporary disciplinary highly-specific context made it possible to detect the most consistent and terminologically clear interpretation of this complex and comprehensive phenomenon, suggested by L. Naumenko (2003). This author, utilizing the general scientific meanings of the word "identification" (sameness, likeness, assimilation, establishing similarities), singles out the precise (in the course of psychology) meaning of the term "identification", considering the latter as the mechanism to display various operations. For example, in the contemporary psychology, the term "identification" is used in the following meanings:

1. the mechanisms of the personality's development, constructing multi-role identity, value orientations, absorption of the behavioural norms and patterns through the assimilation of the subject with the other person;

2. the mechanism of the psychological defence, manifested through the imitation, unconscious mimicking behaviour, and assimilation with the object, who evokes fear or anxiety;

3. the mechanism of projecting, involuntary assigning by the subject to the other person superseded thoughts, motives, desires, 
properties, feelings, and concerns that trigger guilt or anxiety in the subject as well as the subject perceiving the other person as an extension of himself;

4. the mechanism of putting oneself into the other person's place, manifested as empathy and providing for more successful comprehension and interaction; association with a character of a work of fiction (Naumenko, 2003, p. 344).

In social psychology, according to L. Naumenko, identification is a mechanism of the person's socialization, manifested by the subject's association with a particular group or community (social or group identification). In engineer and legal psychology, identification is a mechanism of cognition, recognition through contrasting and comparing one object against the other to establish their similar and distinguishing features. Ethnic psychology defines identification as one of the mechanisms to form and preserve ethnic self-consciousness and its fundamental phenomenon-ethnic identity (Naumenko, 2003, p. 344).

Summing up our brief review, we would like to highlight another theoretical aspect associated with the relativity of the terms "identification" and "identity". In contemporary humanitarian knowledge, the practice of distinguishing identification and identity is not widely established yet, and researchers sometimes equate these concepts. For instance, Z. Golenkova (2000) defines identity as "the process and the result of the individual's association with a group" ( $p$. 415), equating identity with identification as a process. E. Margunov defines social identity as one of the processes of social identification (Mescheryakov \& Zinchenko, 2007, p. 253).

In our research, we make a clear distinction between the terms "identity" and "identification". Identification serves as a foundation for constructing identity, so they correlate as a mechanism, process, and result of such mechanism's operation (process) in the self-consciousness of an individual. V. Mukhina (2000) aptly notes that when we speak about "identity", we emphasize a specific condition, seen as a relatively final result of association. Meanwhile, identification is a process, a specific feature of the socio-psychological mechanisms, leading to such condition.

The development of the personality is accompanied by the continuous identifications that complement, shape, and correct the generalised idea of an individual about him- or herself. Thus, identification serves as a mechanism of constructing and preserving the identity in the process of the personality's evolving and functioning. It is interactional and always serves as the integration of personal and social identifications.

\section{Conclusion}

Therefore, we define identification as a cognitive-and-emotional mechanism of identity construction, due to which the subject constructs his or her sameness.

Individual identification is a mechanism of constructing personal and social identities in the process of socialization and enculturation of an individual, based on the assimilation and/or sameness (mechanisms of self-conscious activity). Collective identification is a mechanism of constructing and preserving collective self-consciousness and collective identity that comprises contrasting and/or comparison with other groups and construction of sameness ( $\approx$ identity) of the group.

Meanwhile, identity results from recognition and emotional assessment of the individualand-group and collective characteristics by an in- 
dividual or group. The relevant others have endorsed such characteristics as a result of constructing the world image, the image of the collective, of individual's or group's self and their place there, based on specific identifying features, including those integrating and differentiating the collective.

Individual identity derives from the formation of individual cognitive and emotional sameness and coherence, driven by an individual and endorsed by others. We interpret the collective identity as a result of a process where the collective is cognitively and emotionally constructing their sameness based on a set of collective features, identifying it as a group and providing interdependence and correlation of the members of such group, as well as its cohesion and unity. Collective identity is manifested in individual identities and comprises such identities. The latter, in their turn, construct and manifest the collective identity itself.

\section{References}

Abushenko, V. L. (1998). Identichnost' (Identity, in Russian). In A. A. Gritsanov (Ed.), Modern Philosophy Dictionary (pp. 400-404). Minsk: Publ. V. M. Skakun.

Aslet, C. (1997). Anyone for England? London: Little Brown.

Bauman, Z. (2010). Identity. Conversations with Benedetto Vecchi. Cambridge: Polity Press.

Boiko, V. V. (2008). Identyfikatsiia (Identification, in Ukrainian). In V. G. Gorodianko (Ed.), Sociological Encyclopaedia (p. 147). Kyiv: Akademvydav.

Erikson, E. H. (1996). Identichnost': yunost' $i$ krizis (Identity, Youth and Crisis, in
Russian). Moscow: Publishing group "Progress".

Golenkova, Z. T. (2000). Identifikatsiya sotsial'naya (Social Identification, in Russian). In V. N. Ivanov \& G. Yu. Semigin (Eds.), Political Encyclopedia (pp. 415-416). Moscow: Mysl.

Grishayeva, L. I. (2007). Osobennosi ispolzovaniya yazyka i kul'turnaya identichnost' kommunikantov (Peculiarities of the Language Use and Cultural Identity of Communicants, in Russian). Voronezh: VGU.

Katanova, E. N. (2007). Nominativnye strategii pri oboznachenii subjekta samoidentifikatsii v samoidentifitsyruyuschem vyskasyvanii (Nominative Strategies of Nominating a Subject of Self-Identification in a Self-Identifying Utterance, in Russian). Language, Communication, and Social Environment, 7, 251260.

Kravchenko, A. I., \& Anurin V. F. (2006). Sotsiologiya: Uchebnik dlya vuzov (Sociology: A Textbook for Higher Education, in Russian). Saint-Petersburg: Peter.

Krysko, V. G. (2001). Sotsialnaya psikhologiya: slovar'-spravochnik (Social Psychology: A Reference Dictionary, in Russian). Minsk: Harvest, Moscow: AST.

Malakhov, Yu. S. (2004). Identichnost' (Identity, in Russian). In A. A. Ivin (Ed.) Philosophy: Encyclopaedical Dictionary (pp. 299-300). Moscow: Gardariki.

Malakhov, Yu. S. (2011). Identichnost' (Identity, in Russian). In V. S. Stenin (Ed.), New Encyclopedia of Philosophy (pp. 7879). Moscow: Mysl. 
Matuzkova, E. P. (2014). Identichnost $i$ lingvokul'tura: metodologiya izucheniya: monografiya (Identity and Linguoculture: Research Methodology: monograph, in Russian). Odessa: Izdatalstvo KP OGT.

Mescheryakov, B. G., Zinchenko, V. P. (Eds.). (2007). Bol'shoi psikhologicheskii slovar' (The Big Dictionary of Psychology, in Russian). Saint-Petersburg: Praim-EVROZNAK.

Mukhina, V. S. (2000). Vozrastnaya psikhologiya (Developmental Psychology, in Russian). Moscow: Akademia.

Naumenko, L. I. (2003). Identifikatsiya (Identification, in Russian). In A. A.Gritsanov (Ed.), Sociology: Encyclopedia (p. 344). Minsk: Interpressservis; Knizhnyi dom.

Petrovsky, A. V., \& Yaroshevsky, M. G. (Eds.) (1985). Kratkii psikhologicheskii slovar' (Concise Dictionary of Psychology, in Russian). Moscow: Politizdat.

Polezhayeva (2004). Problema, opredeleniya identifikatsii kak kategorii v mezhdistsyplinarnom znanii (The Problem, Definition of Identification as a Category of the Interdisciplinary Knowledge, in Russian). In The Materials of the Third International Scientific Conference "Human in the Contemporary Philosophical Concepts" (pp. 156-159). Volgograd: PRINT.

Polezhayeva (2006). Sotsialno-filisofskiy aspekt osmysleniya identifikatsii $i$ nositeley identifikatsionnykh praktik (Sociophilosophic aspect of Comprehension of Identification and Bearers of Identification Practices, in Russian). In A. Nekhayev (Ed.). Omsk Scientific Bulletin (pp. 40-42). Omsk: OmGTU.

Scruton, R. (2006). England: An Elegy. London: Continuum International Publishing Group Ltd.

Stenin, V. S. (Ed.). (2011). Novaya filosofskaya entsyklopediya (New Philosophy Dictionary, in Russian). Moscow: Mysl.

Zakovorotnaya, M. V. (1999). Identishnost' cheloveka. Sotsialno-filosofskiye aspekty (Human Identity, Socio-Philosophic Aspects, in Russian). Rostov-on-Don: SKNTS VSHD. 